\section{Gategory}

Metal-Catalyzed Asymmetric

Synthesis and

Stereoselective

Reactions

\section{Key words}

\section{palladium}

bis(oxazoline)

ligands

alkylazaarenes

nitroalkenes

N-Boc imines

\title{
Palladium-Catalyzed Asymmetric Addition of Alkylazaarenes to Imines and Nitroalkenes
}

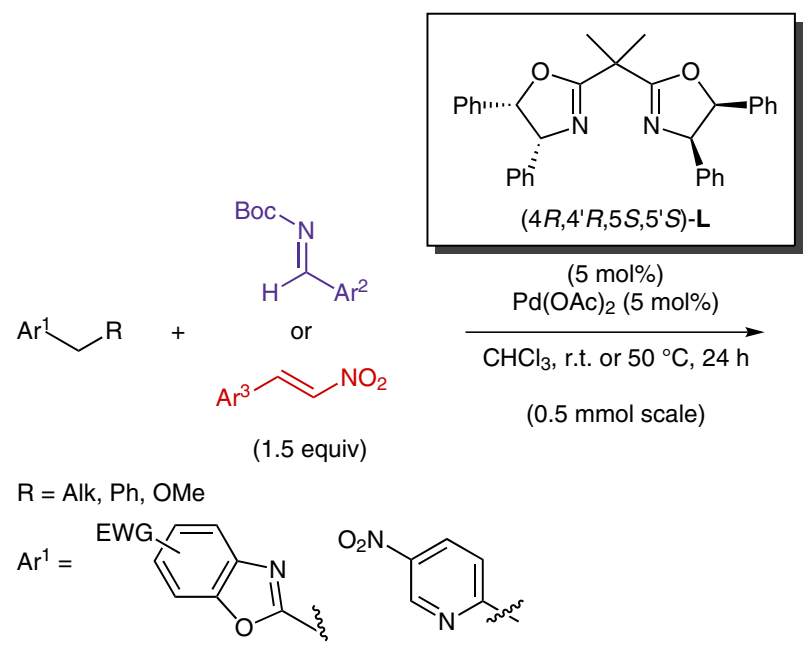

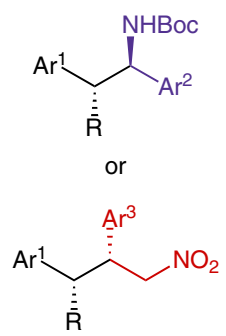

$38-95 \%$ yield dr from $83: 17$ to $>95: 5$

$18-99 \%$ ee

Selected examples:<smiles>O=[N+]([O-])C[C@H](c1cccs1)[C@@H](Cc1ccccc1)c1ccc([N+](=O)[O-])cn1</smiles>

$78 \%$ yield $\mathrm{dr}>95: 5$ $95 \%$ ee<smiles>CCC[C@H](c1nc2ccc(C#N)cc2o1)[C@@H](N)c1ccc([N+](=O)[O-])cc1</smiles>

$>95 \%$ yield $\mathrm{dr}=95: 5$ $91 \%$ ee<smiles>CCCCC(=O)c1ccc2nc([C@@H](N)C(N)c3ccccc3)oc2c1</smiles>

$96 \%$ yield dr $>95: 5$ $95 \%$ ee
Significance: While precedence of the direct addition of alkylazaarenes to imines and nitroalkenes in a racemic manner exists, the authors report the use of a chiral palladium(II)-bis(oxazoline) catalyst that can render this reaction highly diastereo- and enantioselective. The reaction proceeds under practical conditions, employing undried solvent at mild temperatures and under an air atmosphere.
Comment: The use of electron-withdrawing groups on the azaarene facilitates the deprotonation of the benzylic position at lower temperatures, which allows the catalyst to exert high stereocontrol. The corollary is, that the scope is limited to electron-poor azaarenes. However, the authors demonstrate the utility of these products with functionalization of the nitro group on the azaarenes. Treatment of the imine-addition products with mild acid readily deprotects the Boc group. 